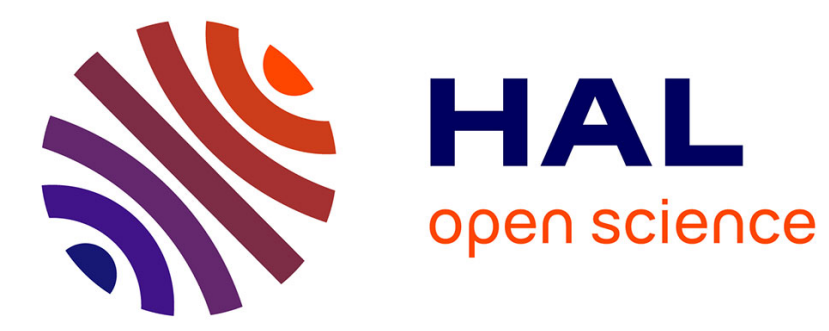

\title{
EXAFS Study on the Glassy State of K1-x(NH4)xI Mixed Crystals
}

\author{
K. Yagi, K. Sakaue, V. Shuvaeva, H. Terauchi
}

\section{To cite this version:}

K. Yagi, K. Sakaue, V. Shuvaeva, H. Terauchi. EXAFS Study on the Glassy State of K1x(NH4)xI Mixed Crystals. Journal de Physique IV Proceedings, 1997, 7 (C2), pp.C2-1163-C2-1164. 10.1051/jp4:19972174 . jpa-00255240

\section{HAL Id: jpa-00255240 https://hal.science/jpa-00255240}

Submitted on 1 Jan 1997

HAL is a multi-disciplinary open access archive for the deposit and dissemination of scientific research documents, whether they are published or not. The documents may come from teaching and research institutions in France or abroad, or from public or private research centers.
L'archive ouverte pluridisciplinaire HAL, est destinée au dépôt et à la diffusion de documents scientifiques de niveau recherche, publiés ou non, émanant des établissements d'enseignement et de recherche français ou étrangers, des laboratoires publics ou privés. 


\title{
EXAFS Study on the Glassy State of $\mathrm{K}_{1-x}\left(\mathrm{NH}_{4}\right)_{x} \mathrm{I}$ Mixed Crystals
}

\author{
K. Yagi, K. Sakaue, V.A. Shuvaeva and H. Terauchi \\ Department of Physics, Kwansei-Gakuin University, Nishinomiya 662, Japan
}

\begin{abstract}
EXAFS study was performed on $\mathrm{K}_{1 \cdot x}\left(\mathrm{NH}_{4}\right)_{x} \mathrm{X}$ mixed crystals with $x=0,0.48$ and 0.68 in order to clarify a local structure of the dipole-glassy state. From the analysis with $k \chi(k)$ spectra, broadening of the peaks indicating the distance between the nearest iodine ions was observed in the glassy state. The backFourier transforms of the iodine ions was well reproduced by the one-shell model in the whole concentration and temperature range. The Debye-Waller factor increases largely with increasing concentration, which is caused by the static disorder. The result indicates existence of the local distortion of lattice formed by iodine ions which is induced by reorientational freezing of ammonium ions with only short-range antiferroelectric correlation.
\end{abstract}

\section{INTRODUCTION}

In recent years, the mixed crystals $\mathrm{K}_{1-x}\left(\mathrm{NH}_{4}\right)_{x} \mathrm{I}$ have attracted much attention due to their dipole-glassy state. Pure ammonium iodide crystals undergo several successive phase transitions, while no transition occurs in pure potassium iodide crystals. By replacing ammonium ions with potassium ions, the phase transitions are suppressed and, in the range of ammonium ion concentration $0.3<x<0.75$, the dipole-glassy state appears below the glass transition temperature $T_{g}$. From the Raman scattering and dielectric measurements, an ammonium ion at the center of iodine octahedron is distorted from $T_{d}$ to $C_{3 v}$ symmetry and has a dipole moment of $1.4 \mathrm{D}$ along the $<111>$ direction $[1,2]$. In the glassy state, reorientational freezing of ammonium ions occurs with only short-range antiferroelectric correlation $[3,4]$. Our previous $x$-ray diffraction study on the mixed crystals has revealed existence of the local distortion of lattice which breaks the symmetry of an fcc lattice [5, 6]. The local distortion is induced by reorientational freezing of arnmonium ions and has short-range antiferroelectric correlation. From our recent $x$-ray structural analysis, the mean structure exhibits relative displacement of the nearest iodine ions along the $\langle 100\rangle$ directions. In this paper, we report results of the EXAFS study on the mixed crystals and discuss about the local and mean structure in the glassy state.

\section{EXPERIMENTAL}

EXAFS measurements were curried out at the beam line BL-7C in Photon Factory of KEK Japan. Powder samples were ground from single crystals which is prepared from aqueous solution with the nominal concentration $x=0,0.5$ and 0.7 . The exact concentration $x=0,0.48$ and 0.68 was determined by chemical analysis. Thickness of the samples was adjusted by checking quality of the EXAFS spectra. The low temperature experiment was performed from ambient temperature down to $10 \mathrm{~K}$ by using a closed-cycle He-gas refrigerator. The synchrotron radiation excited by $2.5 \mathrm{GeV}$ was monochromatized by a double crystal of $\mathrm{Si}(111)$ and focused by a double mirror. The $\mathrm{L}_{\mathrm{r}}$ edge of iodine atom $E=5192 \mathrm{eV}$ was used for the analysis due to its small edge-jump but long tail as compared with the other $\mathrm{L}_{\mathbb{I}^{-}}$and $\mathrm{L}_{\mathbb{I}^{-}}$-edges.

\section{RESULTS AND DISCUSSION}

Fourier transforms and back-Fourier transforms of the k-weighted I L $L_{-}$-edge EXAFS spectra at 10K are shown in Fig. 1 and 2 , respectively. Magnitude of the Fourier transforms decreases noticeably with increasing concentration of ammonium ion. However, imaginary part of the Fourier transforms are quite similar in the whole concentration range and broadening of the peaks indicating the nearest iodine ions is clearly seen with increasing concentration. Significant reduction of the first peak originated from scattering by potassium and ammonium ions, which seems to be mainly due to low scattering amplitude of ammonium ions, don't permit us to analyze this coordination shell and interatomic distances. The glass transition temperatures $T_{g}$ are about $50 \mathrm{~K}$ and $70 \mathrm{~K}$ for $x=0.48$ and 0.68 , therefor the spectra for $x=0.48$ and $0: 68$ belong to the glassy state Model fittings of the back-Fourier transforms are shown in Fig.2 and the fitting parameters are listed in Table 1 with those at the other temperatures. $\Gamma$ and $\Delta E$ values were assumed to be constant for all compounds and temperatures and were not varied while fitting. The Debye-Waller factor increases largely with increasing concentration. The results indicate existence of the local distortion of lattice formed by iodine ions. 


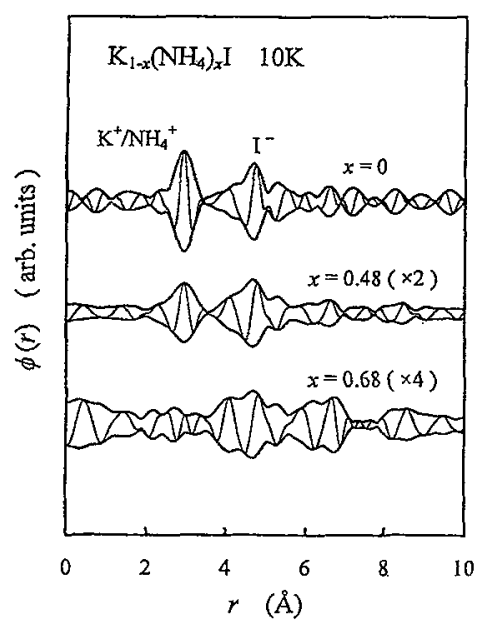

Figure 1: Fourier transforms of the k-weighted I Lredge EXAFS spectra at 10K. Thick and thin curves are absolute and imaginary parts, respectively.

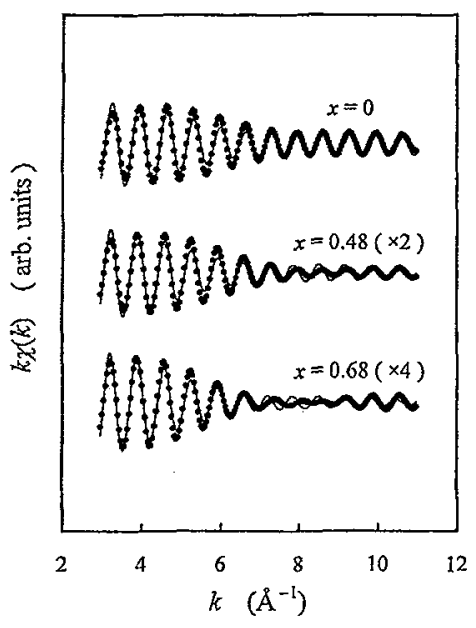

Figure 2: Back-Fourier transforms of the nearest iodine ions. Solid curves and closed circles are caiculated and observed values, respectively.

Reduction of the EXAFS spectra was also observed with increasing temperature due to thermal vibration of ions. The fitting parameters are listed in Table 1 . Interatomic distances are in good agreement with those obtained on the basis of $x$-ray diffraction data and the Debye-Waller factor continuously increases with increasing temperature as shown in Fig.3. At higher temperatures agreement between experimental and calculated $k \chi(k)$ becomes more poor, which is due to growth of relative contribution of different kinds of errors with reduction of signal.

Table 1: The parameters obtained from fitting the $k \chi(k)$ spectra by the one-shell model. The value of $\Gamma$ and $\Delta E$ are fixed on $\Gamma=4 \mathrm{eV}$ and $\angle E=-9 \mathrm{eV}$.

\begin{tabular}{cccccccccc}
\hline$x$ & $\dot{T}(\mathrm{~K})$ & $r(\AA)$ & $\sigma(\AA)$ & $R(\%)$ & $x$ & $T(\mathrm{~K})$ & $r(\AA)$ & $\sigma(\AA)$ & $R(\%)$ \\
\hline \hline 0 & 10 & 4.950 & .0547 & 5.3 & & 150 & 5.014 & .1817 & 7.8 \\
& 50 & 4.954 & .0818 & 3.9 & & 200 & 5.013 & .1897 & 2.1 \\
& 100 & 4.958 & .1196 & 12.8 & & 300 & 4.975 & .2214 & 10.6 \\
& 150 & 4.958 & .1304 & 4.5 & 0.7 & 10 & 5.020 & .1612 & 7.1 \\
& 200 & 4.955 & .1761 & 20.0 & & 50 & 5.020 & .1612 & 6.4 \\
& 300 & 4.955 & .2214 & 21.0 & & 100 & 5.040 & .1732 & 5.8 \\
0.5 & 10 & 4.999 & .1225 & 4.1 & & 150 & 5.038 & .1897 & 7.3 \\
& 50 & 5.003 & .1304 & 4.8 & & 200 & 5.045 & .2025 & 7.9 \\
& 100 & 5.013 & .1581 & 8.3 & & 300 & 5.037 & .2408 & 12.2 \\
\hline
\end{tabular}

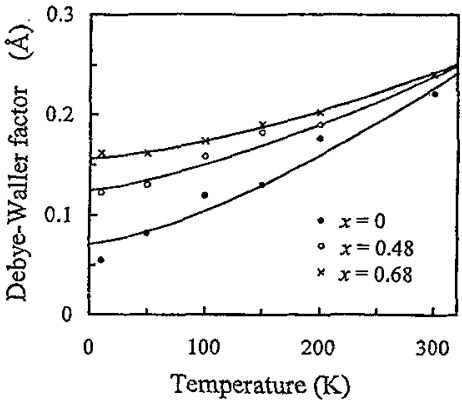

Figure 3: Temperafure dependence of the Debye-Waller factor. The solid curves are given for a guide of eyes.

The $x$-ray structural analysis on $x=0.68$ have been also carried out at $15 \mathrm{~K}$ and the mean structure exhibits the relative displacement of the nearest iodine ions, which has large distribution and lies on the $\langle 100\rangle$ directions. In this model, the three-shell model should be used for the nearest iodine ions in the glassy state. However, the weak EXAFS spectra and the $k \chi(k)$ analysis didn't allow us to find splitting of the peaks. Further details on interatomic distances distribution we hope to obtain on the basis of I K-edge EXAFS.

This work was performed under PF-PAC(No.94G010) of the National Laboratory for High Energy Physics.

\section{References}

[1] W. Joosen, H. Fleurent, C. Bostoen, D. Shoemaker and S. Haussithl, Phys. Rev. B 43 (1991) 11542.

[2] I. Fehst, R. Böhmer, W. Ott, A. Loidl, S. Haussühl and C. Bostoen, Phys. Rev. Lett. 64 (1990) 3139.

[3] J. -F. Berret, C. Bostoen and B. Hennion, Phys. Rev. B 46 (1992) 13747.

[4] Y. Noda, H. Nakao and H. Teranchi, Physica B 213\&214 (1995) 564.

[5] T. Umeki, K. Yagi and H. Terauchi, J. Phys, Soc. Jpn. 63 (1994) 876.

[6] K. Yagi, T. Umeki, H. Terauchi and Y. Noda, Physica B $219 \& 220$ (1996) 281. 